\title{
A Rare-Earth Free SHEV Powertrain and its Control
}

\author{
W U Nuwantha Fernando \\ School of Electrical and Computer Engineering \\ RMIT University \\ Melbourne, VIC 3000, Australia. \\ Phone: +61 (3) 99252873 \\ Email: nuwantha.fernando@rmit.edu.au
}

\author{
K.A.A. Gamage \\ Department of Engineering \\ University of Lancaster \\ Lancaster LA1 4YR, UK. \\ Phone: +44 (0)1524 593873 \\ Email: k.gamage@lancaster.ac.uk
}

\section{Keywords}

$<<$ Automotive electronics $>>,<<$ Battery Management Systems (BMS) $>>,<<$ Control methods for electrical systems $>>,<<$ DC power supply $>>,<<$ Electric vehicle $>>,<<$ Energy converters for HEV $>>,<<$ Generator excitation system $>>,<<$ Power converters for HEV $>>,<<$ Traction application $>>$

\begin{abstract}
A topology of a candidate rare-earth free Series Hybrid Electric Vehicle (SHEV) powertrain and the coordinated control of its components is presented in this paper. The powertrain is fed with a field controlled synchronous generator and a controlled battery bank and drives a $60 \mathrm{~kW}$ rare-earth free traction motor. Simulation results are presented for normal operating conditions and two faulted-mode operating scenarios where the power electronic converter in the system is faulted are investigated.
\end{abstract}

\section{Introduction}

The sustainability of the electric vehicle manufacturing industry and the affordability of electric vehicles are mainly governed by economic implications of individual components in an electric vehicle. Recent research focuses on traction motor types, namely induction motors, permanent magnet motors and switched reluctance motors [6-11]. However, the dependency on rare-earth material in electrical machines of an electric vehicle powertrain places a high economic risk on the electric vehicle manufacturing industry. The need for alternative rare-earth free electric vehicle technology has been recognised in [1-4] and have developed electrical machines to address this issue. The application of rare-earth free technology has been mainly on the traction motor design in the past. In contrast, this paper examines the fully rare-earth free powertrain and its control particularly for series hybrid electric vehicles (SHEVs). SHEVs benefit from a mechanically disconnected powertrain. Hence, the internal combustion engine (ICE) is operated under optimal conditions with reduced emission characteristics [5,7]. Unlike parallel hybrid electric vehicles (PHEVs), the total traction load in a SHEV is delivered by an electrical motor. The following section describes overall system and the basis for the selection of the powertrain topology presented in this paper.

\section{System Description}

Fig. 1 shows a simplified block diagram of the overall control system and the SHEV powertrain considered in this paper. The corresponding system parameters are given in table I. The electric traction is provided by a $60 \mathrm{~kW} 12 / 8 \mathrm{SR}$ motor and is capable of a short time duty of $80 \mathrm{~kW}$ overloaded operation. The switched reluctance motor is known for its low cost manufacturability, capability to operate under high thermal stresses and rugged construction. The power transmission is performed via a $540 \mathrm{~V}$ DC-link. The internal combustion engine (ICE) considered is a $1.3-\mathrm{L} 64-\mathrm{kW}$ engine and is coupled to 


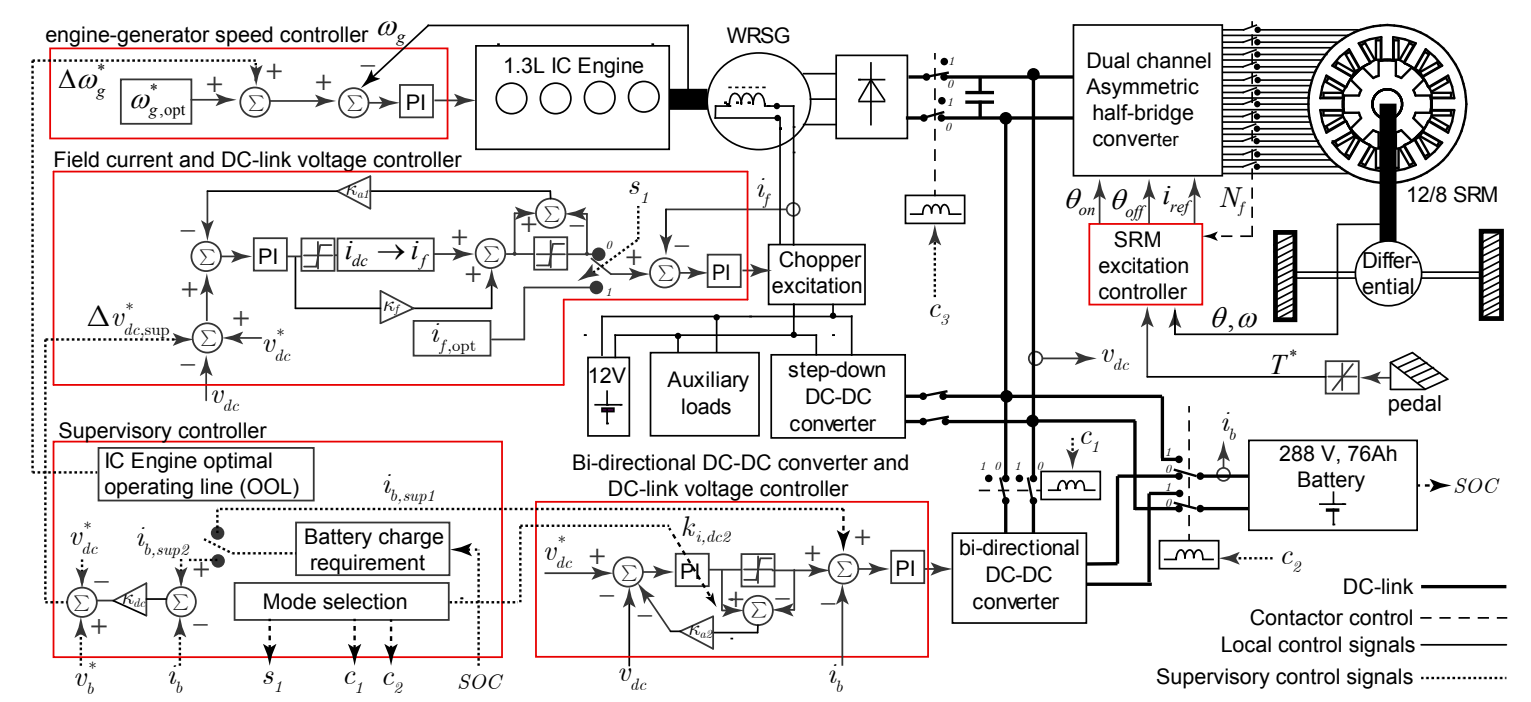

Figure 1: Block diagram of the SHEV powertrain topology and the overall control system.

Table I: SHEV system parameters

\begin{tabular}{l}
\hline \hline SRM and controller parameters: $L_{u}=2.9 \mathrm{mH}, \theta_{o f f, \max }=8 \mathrm{deg}$, \\
$i_{\text {max }}=400 \mathrm{~A}, k_{a d v}=0.805 \mathrm{~ms}, k_{u 1}=0.55, k_{u 2}=0.20$. \\
\hline DC-DC converter parameters: $L_{b}=600 \mu \mathrm{H}, C=19.8 \mathrm{mF} / 0.1 \Omega \mathrm{ESR}$. \\
$k_{p, d c 1}=0.63, k_{i, d c 1}=337.5, k_{p, d c 2}=1.386, k_{i, d c 2}=0(49.5)$. \\
\hline WRSG parameters: $R_{s}=0.101 \Omega, L_{s}=19 \mathrm{mH}, L_{m d}=18.3 \mathrm{mH}$ \\
\hline Field winding and controller parameters: $R_{f}=56.6 \mathrm{~m} \Omega, L_{f}=1.46 \mathrm{mH}$. \\
$k_{p, f}=0.096, k_{i, f}=8.207, k_{p, f c}=0.277, k_{i, f c}=1.98, \kappa_{f}=1$. \\
\hline Engine and throttle controller: $J_{e} \approx 0.5 \mathrm{kgm}^{2}, \tau_{e} \approx 0.1 \mathrm{~s}^{-1}$, \\
$k_{p, e}=2.09, k_{i, e}=4.5$. \\
\hline Supervisory controller: $\kappa_{d c}=-0.5 \mathrm{~V} / \mathrm{A}$ \\
\hline
\end{tabular}

a $62 \mathrm{~kW}$ generator. The rare-earth free generator options for the powertrain are found to be the induction generator, wound rotor synchronous generator, in addition to the switched reluctance generator. As mentioned earlier, the engine in a SHEV power train is operated at its optimal level and this is typically at a constant shaft speed. Therefore the power output from the generator to the powertrain is controlled in a discrete on/off manner [12]. While an induction generator will require a controlled 3-phase active rectifier for its operation, a switched reluctance generator will also require an asymmetric half bridge converter for its control. In contrast, the output of a wound rotor synchronous generator (WRSG) can be rectified with a diode-bridge rectifier with the field current controlled with simple DC voltage chopper. Due to its simple control and low switching device count, the latter option is adopted in the powertrain presented in this paper. The generator excitation is controlled by a chopper circuit operating with an auxiliary $12 \mathrm{~V} \mathrm{DC}$-link. The WRSG output is rectified to a nominal $540 \mathrm{~V} \mathrm{DC}$-link. The DC-link is also sourced by a 76 Ah $288 \mathrm{~V}$ battery interfaced with a non-isolated bi-directional DC-DC converter. The traction motor is driven by this $540 \mathrm{~V}$ DC-link with a two-channel asymmetric half bridge converter topology $[13,14]$. The detailed system parameters are given in table I.

\section{System Operation and Control}

The supervisory controller determines the operation of the ICE and WRSG. It is also referred to as the auxiliary power unit (APU) controller [15] in cases where the engine throttle control and load sharing control are combined into one unit. However, in this paper the controllers are considered in modular architecture as shown in Fig. 1. Two modes known as load leveling mode and power follower or power tracking mode [15] also referred to as thermostatic mode and energy follower mode [16,17] are facilitated by the supervisory controller.

The control of the bidirectional DC-DC converter, WRSG field current and DC-link voltage controller and the engine controller are shown in block diagram format in Fig. 1. The DC-DC converter con- 
trol is formulated with DC-link voltage regulation capability and with the ability to impose charging or discharging of the battery with the $i_{b, s u p 1}$ command. The WRSG excitation controller is also formulated with a voltage adjustment variable $\Delta v_{d c, s u p}^{*}$ command. This allows indirect battery charging or discharging capability under DC-DC converter bypassed operation at lower DC-link voltage. The mode of operation is dictated by the supervisory controller.

Table II: Summary of the operating conditions and controller activity

\begin{tabular}{c|l}
\hline \hline Normal operating condition & Controller action \\
\hline Load leveling mode & $c_{1}=0, c_{2}=0, c_{3}=0, s_{1}=1$. \\
& $\Delta v_{d c, \text { sup }}^{*}=0, \Delta \omega_{g}^{*}=0$ and $i_{d c, s u p 1}^{*}=0$. \\
& $k_{i, d c 2} \neq 0$ issued by the supervisory controller. \\
\hline Power follower mode & $c_{1}=0, c_{2}=0, c_{3}=0, s_{1}=0$. \\
& $k_{i, d c 2}=0$ and $\Delta v_{d c, s u p}^{*}=0$. \\
& $\Delta \omega_{g}^{*}$ and $i_{d c, s u p 1}^{*}$ issued by the supervisory controller. \\
\hline \hline Faulted operating condition & Controller action \\
\hline DC-DC converter failure & $c_{1}=1, c_{2}=0, c_{3}=0, s_{1}=0$. \\
& $\Delta v_{d c, s u p}^{*}=0$. Variable $\Delta \omega_{g}^{*}$. \\
\hline DC-DC converter failure (bypassed) & $c_{1}=1, c_{2}=1, c_{3}=0, s_{1}=0$. \\
& Variable $\Delta v_{d c, s u p}^{*}$ and $\Delta \omega_{g}^{*}$. \\
\hline
\end{tabular}

The engine controller regulates engine speed at $\omega_{g}^{*}$. The engine speed command $\omega_{g}^{*}=\omega_{g, o p t}^{*}+\Delta \omega_{g}^{*}$ consists of a nominal speed command $\omega_{g, \text { opt }}^{*}$ and a speed modification command $\Delta \omega_{g}^{*}$ issued by the supervisory controller to maintain engine either in load leveling mode or power follower mode. Load leveling mode is achieved by operation of the bi-directional DC-DC converter in DC-link voltage control mode. The control gain $k_{i, d c 2} \neq 0$ is issued by the supervisory controller. In the power follower mode, DC-link voltage control is performed by the generator-excitation. The DC-DC converter voltage controller integral gain $k_{i, d c 2}=0$ (nominal setting) such that the battery contributes only to transient power demands. The ICE speed is kept within an optimal operating line (OOL) by an engine speed modification command $\Delta \omega_{g}^{*}$ issued by the supervisory controller.

The torque command $T^{*}$ is issued by the driver via the accelerator pedal. This is converted to SR motor excitation commands. The $12 / 860 \mathrm{~kW}$ SR motor considered in this study has a base speed of $3250 \mathrm{rpm}$ at a DC-link voltage of $540 \mathrm{~V}$ and $1500 \mathrm{rpm}$ at a DC-link voltage of $288 \mathrm{~V}$. A voltage of $288 \mathrm{~V}$ is considered only for the DC-DC converter faulted operating condition.

\section{Simulation results}

Simulations are performed for the SHEV presented in Fig. 1. One healthy condition and two cases under a DC-DC converter faulted mode outlined in table II are considered in the simulations.

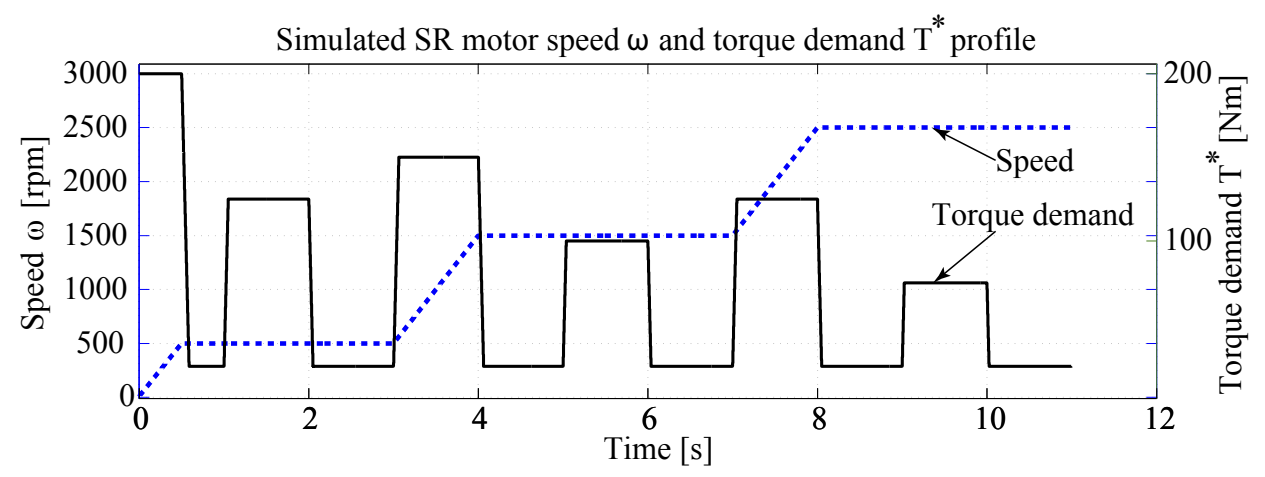

Figure 2: Simulated traction motor speed $\omega$ and torque demand $T^{*}$.

In each case, the traction motor torque demand $T^{*}$ and the motor speed $\omega$ are varied according to the profile given in Fig. 2. The speed demand varies from a near zero value to 500rpm, 1500rpm and finally to $2500 \mathrm{rpm}$. At each speed, the SR traction motor torque demand is varied between $200 \mathrm{Nm}$ and $75 \mathrm{Nm}$ 
Healthy powertrain operation in power follower mode with $i_{b, \text { sup } 1}^{*}=-10 \mathrm{~A}$ command

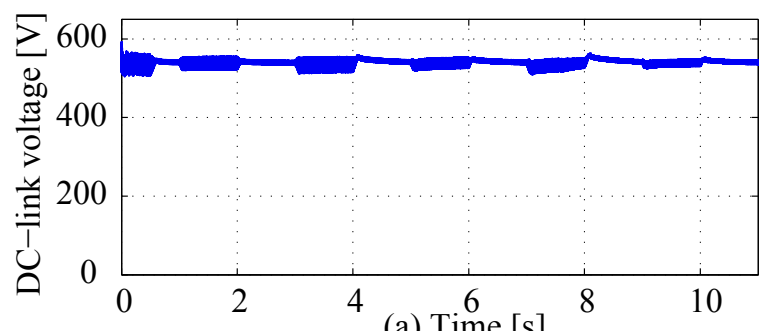

$\mathrm{Bi}$-directional DC-DC converter faulted (open-circuited)

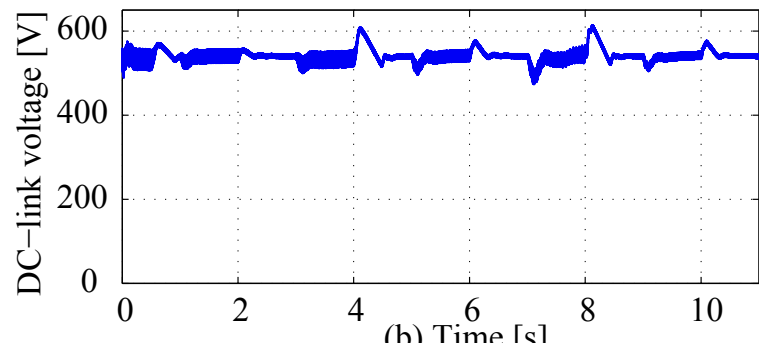

(b) Time $[\mathrm{s}]$

Bi-directional DC-DC converter faulted (open-circuited \& bypassed) powertrain operation at a lower DC-link voltage

sourced directly by the battery and the WRSG/rectifier with $i_{b, \text { sup } 2}{ }^{*}=-10 \mathrm{~A}$ command

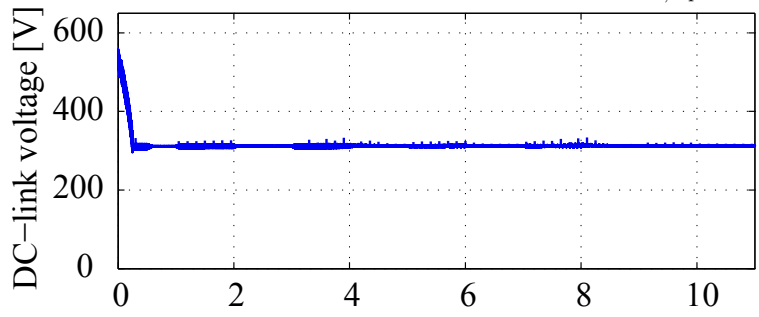

(c) Time $[\mathrm{s}]$

Figure 3: (a),(b) and (c) DC-link voltage waveforms for one healthy scenario and two faulted operating scenarios.

as shown in Fig. 2. The engine speed is regulated at the nominal $1500 \mathrm{rpm}$ value i.e. with $\Delta \omega_{g}^{*}=0$ during all the operating conditions in this simulation.

Fig. 3 presents the DC-link voltage response, Fig. 4 the battery and the rectifier average DC current production, and Fig. 5 the SR motor instantaneous and average torque production associated with the three cases of table II. The subfigure (b) present the operation of the powertrain with the stand-alone WRSG condition. During this mode of operation, a higher DC-link voltage overshoot is observed due to the incapability of reverse current flow. However, for the operating condition considered in the simulations, this voltage overshoot is confined to a maximum of approximately 600V. Fig. 3 (a) present the healthy condition and hence superior DC-link voltage regulation characteristics, mainly due to the availability of the DC-DC converter and its rapid DC-link voltage control capability. Fig. 3 (c) present the DC-link voltage during DC-DC converter bypassed operation. Initially the DC-link voltage is brought down to the battery terminal voltage level and the battery is then clamped on to the DC-link at approximately $t=0.2 \mathrm{~s}$. The DC-link voltage remains nearly constant. However, closer examination reveals minor variations of the DC-link voltage due to the indirect control of the battery average current via $\Delta v_{d c \text {,sup }}^{*}$ command imposed by the supervisory controller.

In Fig. 4 (a) and (c), the controllability of the average DC-current of the battery is utilized. This is performed by imposing an average DC current command of $-10 \mathrm{~A}$ for battery charging during steady state conditions. It can be observed from both Fig. 4 (a) and (c) that the average battery current converges to the dark dotted line of $-10 \mathrm{~A}$ and a longer time steady-state simulation further confirms this. Fig. 4 (h) present the scenario in which the battery is directly clamped to the DC-link. In this mode of operation, the transient power is also delivered by the battery at a lower DC-link voltage. 
Healthy powertrain operation in power follower mode with $i_{b, s u p 1}^{*}=-10 \mathrm{~A}$ command

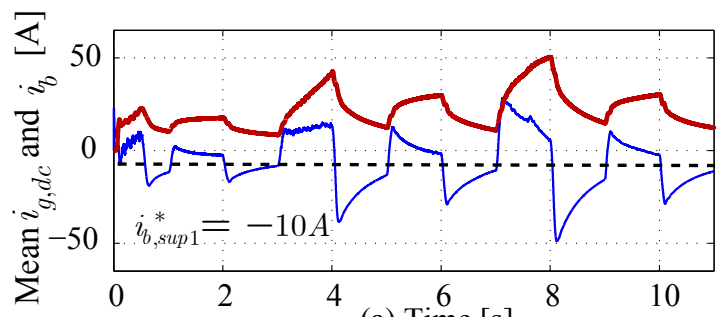

(a) Time $[\mathrm{s}]$

Bi-directional DC-DC converter faulted (open-circuited)

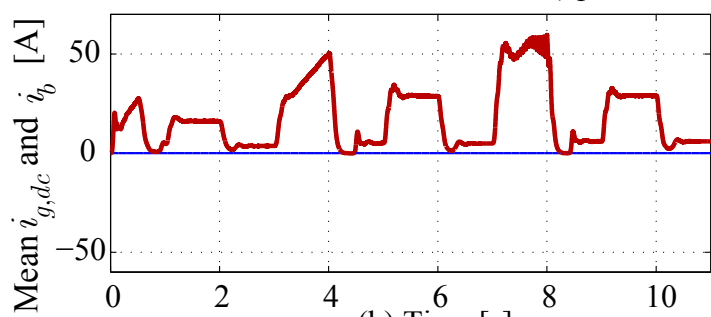

(b) Time $[\mathrm{s}]$

$\mathrm{Bi}$-directional $\mathrm{DC}-\mathrm{DC}$ converter faulted (open-circuited \& bypassed) powertrain operation at a lower DC-link voltage

sourced directly by the battery and the WRSG/rectifier with $i_{b, \text { sup } 2}^{*}=-10 \mathrm{~A}$ command

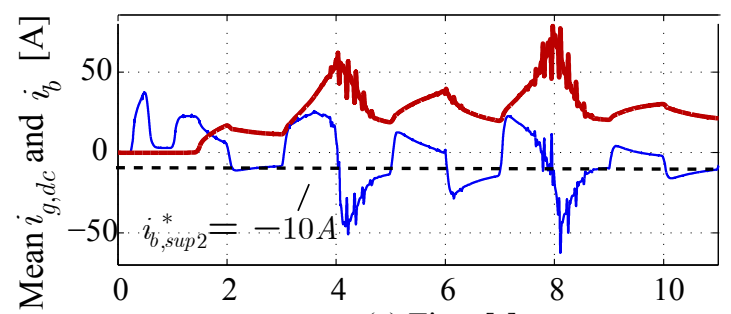

(c) Time $[\mathrm{s}]$

Mean battery current $i_{b}$

Mean rectifier DC current $i_{g d c}$

Figure 4: (a),(b) and (c) Generator-rectifier and battery mean current waveforms for one healthy scenario and two faulted operating scenarios.

\section{Conclusion}

The powertrain of a rare earth-free SHEV and its control design has been presented in this paper. The task of the supervisory controller has been explained. The fault accommodation capability during powertrain faults such as the loss of the bi-directional converter are outlined. Main fault scenarios, viz. the operation with only the WRSG-rectifier in addition to the possibility of direct connection of the battery during faulted conditions has been considered. Simulation results confirm the successful operation of the presented system with the proposed control structure and the successful load sharing during these powertrain faulted conditions.

\section{References}

[1] P. Watterson, W. Wu, B. Kalan, H. Lovatt, G. Prout, J. Dunlop, and S. Collocott, "A switched-reluctance motor/generator for mild hybrid vehicles," in Electrical Machines and Systems, 2008. ICEMS 2008. International Conference on, Oct 2008, pp. 2808-2813.

[2] T. Imakawa, K. Chimata, N. Hoshi, A. Chiba, M. Takemoto, and S. Ogasawara, "Characteristic measurements of switched reluctance motor on prototype electric vehicle," in Electric Vehicle Conference (IEVC), 2012 IEEE International, March 2012, pp. 1-8. 
Healthy powertrain operation in power follower mode with $i_{b, \text { sup } 1}{ }^{*}=-10 \mathrm{~A}$ command

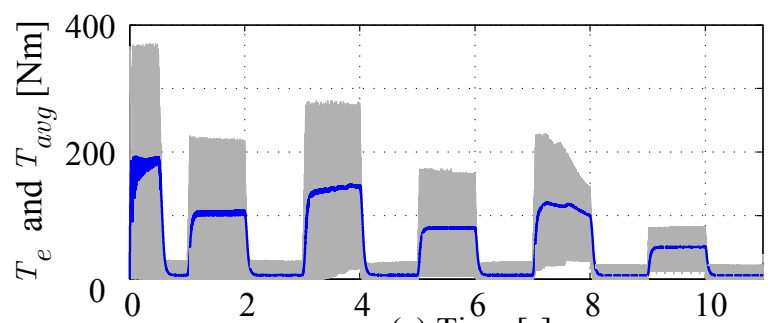

(a) Time $[\mathrm{s}]$

Bi-directional DC-DC converter faulted (open-circuited)

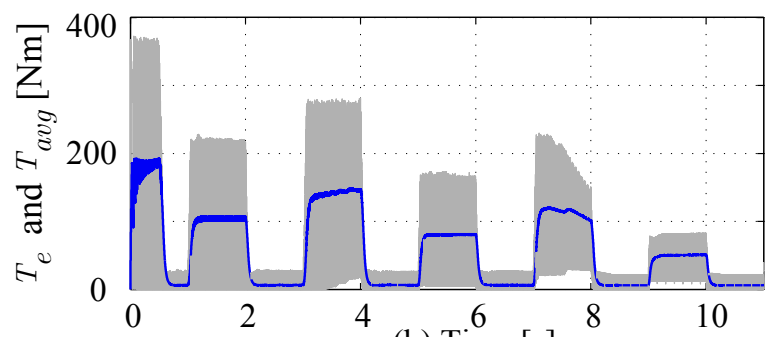

(b) Time $[\mathrm{s}]$

Bi-directional DC-DC converter faulted (open-circuited \& bypassed) powertrain operation at a lower DC-link voltage

sourced directly by the battery and the WRSG/rectifier with $i_{b, s u p 2}^{*}=-10 \mathrm{~A}$ command

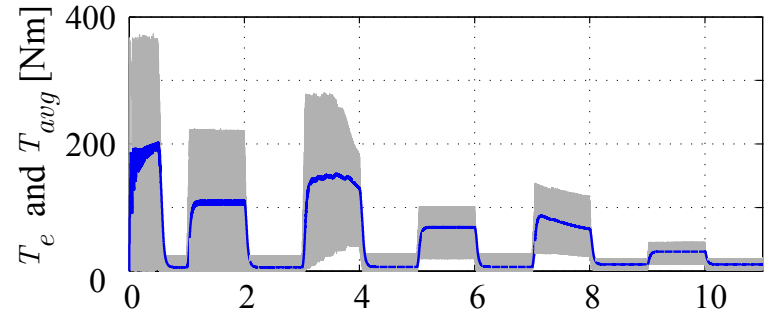

(c) Time $[\mathrm{s}]$

SRM instantaneous torque $T_{e} \longrightarrow$ SRM mean torque production

Figure 5: (a),(b) and (c) SR motor instantaneous and mean torque waveforms for one healthy scenario and two faulted operating scenarios.

[3] A. Chiba, Y. Takano, M. Takeno, T. Imakawa, N. Hoshi, M. Takemoto, and S. Ogasawara, "Torque density and efficiency improvements of a switched reluctance motor without rare-earth material for hybrid vehicles," Industry Applications, IEEE Transactions on, vol. 47, no. 3, pp. 1240-1246, May 2011.

[4] N. Schofield, S. Long, D. Howe, and M. McClelland, "Design of a switched reluctance machine for extended speed operation,” Industry Applications, IEEE Transactions on, vol. 45, no. 1, pp. 116-122, Jan 2009.

[5] S. Barsali, C. Miulli, and A. Possenti, "A control strategy to minimize fuel consumption of series hybrid electric vehicles," Energy Conversion, IEEE Transactions on, vol. 19, no. 1, pp. 187 - 195, march 2004.

[6] W. Fernando and M. Barnes, "Model based optimization and fault tolerant control of permanent magnet machines with harmonic injection pulse width modulation," in Vehicle Power and Propulsion Conference (VPPC), 2011 IEEE, sept. 2011, pp. $1-6$.

[7] L. Parsa and H. Toliyat, "Fault-tolerant interior-permanent-magnet machines for hybrid electric vehicle applications," Vehicular Technology, IEEE Transactions on, vol. 56, no. 4, pp. 1546 -1552, july 2007.

[8] M. Zadeh, B. Asaei, and M. Hamzeh, "Performance analysis of an electric vehicle in faulty inverter mode," in Power and Energy Conference, 2008. PECon 2008. IEEE 2nd International, dec. 2008, pp. $731-736$.

[9] C. Ifedi, B. Mecrow, S. Brockway, G. Boast, G. Atkinson, and D. Kostic-Perovic, "Fault tolerant in-wheel motor topologies for high performance electric vehicles," in Electric Machines Drives Conference (IEMDC), 2011 IEEE International, may 2011, pp. 1310-1315.

[10] D. Diallo, M. Benbouzid, and A. Makouf, "A fault-tolerant control architecture for induction motor drives in automotive applications," Vehicular Technology, IEEE Transactions on, vol. 53, no. 6, pp. 1847 - 1855, nov. 2004. 
[11] M. Benbouzid, D. Diallo, and M. Zeraoulia, "Advanced fault-tolerant control of induction-motor drives for ev/hev traction applications: From conventional to modern and intelligent control techniques," Vehicular Technology, IEEE Transactions on, vol. 56, no. 2, pp. 519 -528, march 2007.

[12] X. Zhang and M. Chris, "Integrated design of powertrain controllers in series hybrid electric vehicles for efficiency enhancement and battery lifetime extension," in World Electric Vehicle Journal, May 2009.

[13] A. Radun, C. Ferreira, and E. Richter, "Two-channel switched reluctance starter/generator results," Industry Applications, IEEE Transactions on, vol. 34, no. 5, pp. 1026 -1034, sep/oct 1998.

[14] W. Fernando, M. Barnes, and O. Marjanovic, "Excitation control and voltage regulation of switched reluctance generators above base speed operation," in Vehicle Power and Propulsion Conference (VPPC), 2011 IEEE, sept. 2011, pp. $1-6$.

[15] P. Brooking and J. Bumby, "An integrated engine-generator set with power electronic interface for hybrid electric vehicle applications," in Power Electronics, Machines and Drives, 2002. International Conference on (Conf. Publ. No. 487), june 2002, pp. 153 - 158.

[16] Z. Wang, W. Li, and Y. Xu, "A novel power control strategy of series hybrid electric vehicle," in Intelligent Robots and Systems, 2007. IROS 2007. IEEE/RSJ International Conference on, 29 2007-nov. 2 2007, pp. 96 -102 .

[17] B. Huang, X. Shi, and Y. Xu, "Parameter optimization of power control strategy for series hybrid electric vehicle," in Evolutionary Computation, 2006. CEC 2006. IEEE Congress on, 0-0 2006, pp. 1989 -1994. 